\title{
El sistema europeo de Derechos humanos: en particular, el riesgo de que la dignidad humana pierda su carácter núclear a favor de la autonomía personal
}

\section{The European system of Human Rights: in particular, the risk that human dignity will lose its core character in favor of personal autonomy}

Tomás Prieto Álvarez.

\section{RESUMEN}

Poco después de la aprobación de la Declaración Universal de Derechos Humanos de la ONU, con la creación del Consejo de Europa y la redacción del Convenio Europeo de Derechos Humanos de 1950, arrancó en Europa un sistema propio de protección colectiva de los derechos humanos, cuya guardia suprema se confió al Tribunal Europeo de Derechos Humanos. La base del sistema no podía ser otro que la dignidad humana, fundamento de todos los derechos y eje mismo de todo el Derecho.

El sistema europeo ha sido protagonista de indudables avances en materia de derechos humanos en el Continente. El riesgo al que ahora se enfrenta es que la base de este sistema de derechos (la dignidad humana, acabamos de decir) sea desplazada hacía el derecho de autodeterminación de las personas o principio de autonomía personal, tal como lo ha definido e interpretado el Tribunal Europeo de Derechos Humanos. En este trabajo se intenta demostrar que se trata de una verdadera y grave amenaza.

DESCRITORES (KEYWORDS): Europa, derechos fundamentales, dignidad humana, autonomía personal.

Shortly after the adoption of the Universal Declaration of Human Rights of the UN, with the creation of the Council of Europe and the drafting of the European Convention on Human Rights of 1950, a European system of collective protection of human rights was launched in Europe. Supreme Court was entrusted to the European Court of Human Rights. The basis of the system could not be other than human dignity, the foundation of all rights and the very axis of all law.

The European system has been the protagonist of undoubted advances in the field of human rights in the continent. The risk that now faces is that the basis of this system of

\footnotetext{
${ }^{1}$ Profesor titular de Derecho Administrativo - Universidad de Burgos (España). E-mail: tomaspri@ubu.es
} 
rights (human dignity, just said) is displaced to the right of self-determination of the people or principle of personal autonomy, as defined and interpreted by the Court European Commission on Human Rights. In this work we try to show that it is a real and serious threat.

\section{INTRODUCCIÓN}

La más antigua de las organizaciones que persigueun ideal de integración europeaes el Consejo de Europa, que vio la luz con el Tratado de Londres de 5 de mayo de 1949. Casi a la par arrancó la propuesta de integración "economicista" que se concretaría, inicialmente, en el Tratado de creación de la CECA de 1951 y, particularmente, en el Tratado de Roma de 1957, con el que nació la Comunidad Económica Europea. Puede hablarse, desde luego, deléxito de la integración comunitaria. Pero ha de advertirse que quienes idearon este ambicioso proyecto "comunitario" — que serían bautizados más tarde como los "padres de Europa" - no pensaron, como su móvil inspirador, en el mero progreso económico de sus naciones, para el cual una integración con sus vecinos se revelaba como muy provechosa: lo que Schumann y Adenauer - muy singularmente- perseguían era una Europa que no viviera más guerras, una razón humanista... de derechos y de dignidad humana, a cuyo servicio propusieron, eso sí, como punta de lanza, una integración económica, que sería más tarde, poco a poco, también política. Es por lo que la progresiva toma en consideración de los derechos personales desde las instancias comunitarias europeas era una consecuencia lógica. Se entiende, así, tanto la redacción de la Carta de Derechos Fundamentales de la Unión Europea - a la que el artículo 6 del Tratado de Funcionamiento otorga ahora el mismo valor jurídico que los Tratados-, como el hecho de que el mismo artículo prevea la — de momento fallida — adhesión de la Unión al Convenio Europeo para la Protección de los Derechos Humanos y de las Libertades Fundamentales, de 4 de noviembre de 1950 (en adelante CEDH).

Pero volvamos al primer proyecto de unificación, que es el que aquí nos ocupará. El propósito integrador de quienes firmaron el Tratado de Londres, y más tarde el CEDH, queda patente en el Preámbulo del Convenio, cuyo párrafo tercero señalala finalidad misma del Consejo de Europa: "realizar una unión más estrecha entre sus 
miembros", para lo que considera "uno de los medios" "la protección y el desarrollo de los derechos humanos y de las libertades fundamentales". El Preámbulo termina acogiendo la resolución de los Estados europeos firmantes de "tomar las primeras medidas adecuadas para asegurar la garantía colectiva de algunos de los derechos enunciados en la Declaración Universal (DUDH de la ONU de 1948)”. Es decir, sobre la base de la DUDH se quiere construir "un sistema regional de protección de ciertos derechos que reforzara su garantía colectiva y efectividad real", y se pretende que esta voluntad de desarrollo de tales derechos fuera un "medio" que contribuyera a "realizar una unión más estrecha" entre los europeos. Como también dice el profesor García Roca, se partía, en definitiva de la idea de que "los derechos humanos son parte de la mejor noción de Europa"2. Dicho de otra manera, una integración que no incluyera un sistema común básico de derechos de los europeos sería una integración fallida.

Nos recuerda el profesor Michel Levinet que el citado CEDH constituye una "verdadera Carta Magna de los cuarenta y siete Estados miembros del Consejo de Europa”, en lo que a derechos se refiere. Dice en otro momento que se trata de una "constitución en el sentido material del término", afirmación que puede o no compartirse, según entienda uno qué es un Constitución. Lo que parece claro es la función del Convenio: como dice el mismo autor francés, el CEDH se erige en base o suelo ("socle" es la palabra francesa que usa) de la protección de los derechos y libertades en el seno del Derecho constitucional europeo ${ }^{3}$. Podemos hablar de un "suelo" protector en la medida en que las disposiciones del Convenio se revelan como un estándar mínimo sobre derechos humanos que los Estados pueden perfectamente sobrepasar ${ }^{4}$.

Paralelamente, no puede perderse de vista que el CEDH confía primariamente a los Estados la tutela de los derechos que recoge. Pronto recordó el Tribunal Europeo de Derechos Humanos (TEDH) — que será el protagonista central de estas breves líneas-

${ }^{2}$ Vid. GARCÍA ROCA, J., "El Preámbulo, contexto hermenéutico del Convenio: un instrumento constitucional del orden público europeo", en GARCÍA ROCA, J., y SANTOLAYA, P. (coords.), La Europa de los Derechos. El Convenio Europeo de Derechos Humanos, CEPC, Madrid, 2005, p. 45.

${ }^{3}$ LEVINET, M., "La Convention européenne des droits de l'homme, socle de la protection des droits de l'homme dans le droit constitucionnel européen", Revue Française de Droit Constitutionnel, n 86, 2011, p. 227.

${ }^{4}$ Se recuerda que el artículo 53 del CEDH dice que "Ninguna de las disposiciones del presente Convenio será interpretada en el sentido de limitar o perjudicar aquellos derechos humanos y libertades fundamentales que podrán ser reconocidos conforme a las leyes de cualquier Alta Parte Contratante o en cualquier otro Convenio en el que esta sea parte". 
que "el mecanismo de protección instaurado por el Convenio reviste un carácter subsidiario en relación a los sistemas nacionales de garantía de los derechos humanos. El Convenio confía, en primer lugar, a cada uno de los Estados Contratantes el cuidado de asegurar el goce de los derechos y libertades que consagra. Las instituciones creadas por él contribuyen a esa finalidad, pero no entran en juego sino por la vía contenciosa y después de haberse agotado las vías de recursos internos" (sentencia Handyside c. Reino Unido, de 7 de diciembre de 1976, ap. 48) ${ }^{5}$. Por lo tanto, la tutela judicial de este conjunto de derechos se confía, en primer lugar, al juez interno, que, en virtud del principio de subsidiaridad, constituye el juez de Derecho común.

Interesa resaltar aquí que este juez nacional no tiene la última palabra sobre la interpretación de las disposiciones del Convenio: es bien conocido que esta corresponde al TEDH, que deviene, pues, en "guardián supremo" del $\mathrm{CEDH}^{6}$. Hoy pocas dudas quedan de que el corpus jurisprudencial construido por los jueces de Estrasburgo durante estas décadas reviste una significación particular, cada vez en más campos, hasta el punto de que se puede hablar de una europeización de los derechos fundamentales. En esta línea, también se ha dicho, se ha ido configurando un "orden público europeo"7. Se comprenden estas valoraciones si se considera que el Tribunal, en palabras de quien tiempo atrás fue su presidente, "tiene necesariamente un papel tanto creador como intérprete" ${ }^{8}$ en relación con los derechos garantizados por el Convenio.

En el papel desempeñado por el sistema europeo de derechos humanos durante estas décadas no es difícil, pues, identificar notables aportaciones en relación con los derechos de los europeos, lo que someramente ejemplificaré. Pienso, no obstante, que merecen un mayor detenimiento las sombras que se observan en labor del TEDH desde hace unos años; esto,tanto por la relevancia de estas sombras como porque quizá no se hayan percibido por todos. Baste ahora decir que se ha escrito, no hace mucho, que "asistimos al suicidio del derecho", de la mano de "una jurisprudencia suicida" (valga la

\footnotetext{
${ }^{5}$ Es por lo que el artículo 35 del CEDH dice que "Al Tribunal no podrá recurrirse sino después de agotar las vías de recursos internas, tal como se entiende según los principios de derecho internacional generalmente reconocidos y en el plazo de seis meses a partir de la fecha de la resolución interna definitiva".

${ }^{6}$ LEVINET, M., op. cit., p. 235.

7 Vid. GARCÍA JIMÉNEZ, E., El Convenio Europeo de Derechos Humanos en el umbral del siglo XXI, Tirant lo Blanc, Valencia, 1998, pp. 33 y ss.

${ }^{8}$ COSTA, J.-P., "La Cour européenne des droits de l'homme: un juge qui gouverne?", Mélanges G. Timsit, Bruselas, 2004, p. 67.
} 
redundancia) del alto Tribunal europeo ${ }^{9}$. Y es que, como revela el título de este trabajo, la dignidad humana corre el riesgo de perder el carácter de base del sistema jurídico de los derechos, que parece trasladarse a la autonomía de las personas. Se comprenderá que el tema no es menor, y que en modo alguno puede ventilarse en estas escuetas páginas: solo lo dejaré apuntado a grandes rasgos. Y lo haré comenzando por una somera referencia a algunas luces aportadas desde el sistema de derechos que nos ocupa, para luego detenerme en las sombras amenazadorasprovocadas últimamente por la jurisprudencia europea.

\section{LAS LUCES EN EL PAPEL DEL CEDH Y DEL TEDH COMO INTEGRADORES EN MATERIA DE LOS DERECHOS}

Al sancionarse el CEDH parece evidente que latía el deseo de la instauración de un orden jurídico europeo de los derechos del hombre ${ }^{10}$, sobre la base de la Declaración Universal de la $\mathrm{ONU}^{11}$. De ahí que se pueda hablar de un sistema europeo de protección de los derechos humanos ${ }^{12}$. Según reza su Preámbulo, el Convenio parte de "una concepción y un respeto comunes de los derechos humanos", lo que fuerza a uniformar en una medida suficiente el contenido - y los límites - de los derechos, asegurándose para estos, en buena ley, un cierto estándar "europeo": se trata, en el fondo, de la razón de ser de la CEDH y del TEDH. Ahora bien, sobre el Tribunal ha recaído la fundamental responsabilidad de perfilar unos derechos escuetamente definidos o descritos en el Convenio; y en este papel le ha correspondido conciliar el establecimiento de aquel orden europeo con el respeto del pluralismo jurídico y cultural de los Estados miembros, otorgándoles un margen de apreciación en materia de derechos. Cierto que tal margen pone en bandeja la tentación del relativismo moral y

\footnotetext{
9 Vid. EDELMAN, B., "Naissance de l'homme sadien", Droits. Revue française de théorie, de philosophie et de culture juridique, no 49, 2009, pp. 124 y 133.

${ }^{10}$ De cuyo contenido y proceso de instauración, con el telón de fondo de la CEDH y la contribución del TEDH, se ocupa el ya citado Jean-Paul COSTA en "La Cour Européenne des Droits de l'Homme: vers un ordre juridique européen?", en Mélanges en hommage à Louis Edmond Pettiti, Bruylant, Bruselas, 1998, p. 197.

${ }^{11}$ Bien entendido que "esta Declaración tiende a asegurar el reconocimiento y aplicación universales y efectivos de los derechos en ella enunciados", dice el considerando segundo del CEDH.

12 Tal es el título de la obra dirigida por GARCÍA DE ENTERRÍA, E., LINDE PANIAGUA, E., ORTEGA, L. y SÁNCHEZ MORÓN, M., publicada por Civitas (2ª ed. de 1983).
} 
con él, de la fragmentación de los derechos, si no se determina con rigor lo que en estos es esencial y común, vinculante para todos.

Pero, como ya se ha indicado, el TEDH ha realizado una labor depuradora y hasta creadora del Derecho en el ámbito europeo a partir del texto del CEDH. Me permito citar dos ejemplos significativos, entre muchos posibles:

En primer lugar, el artículo 2 del CEDH, al recoger el derecho a la vida de las personas, contempla aún la posibilidad de "una condena que imponga la pena capital". Sin embargo, la evolución en este punto, desde el lejano año 1950, de la mayoría de los países europeos determinó la de las propias instancias europeas - concretada normativa $^{13}$ y jurisprudencialmente ${ }^{14}$ - , que a vez sirvió para depurar la legislación y las praxis europeas sobre la pena de muerte o sobre las extradiciones que pudieran derivar en ella.

En otra línea, el TEDH ha ensayado una progresiva ampliación del ámbito material de aplicación del artículo 8.1 del CEDHsobre el derecho al respeto de la vida privada, con indudables aspectos positivos y necesarios. Así, relevante en este punto es el ejercicio de la sexualidad, sobre el cual la referencia obligada es la célebre sentencia Dudgeon c. Reino Unido, de 22 de octubre de 1981 acerca de la condena penal del ejercicio de la homosexualidad; fallo que forzó la modificación de la legislación en Irlanda del Norte. El profesor Marguénaud considera que esta sentencia es "seguramente una de las más grandes sentencias jamás rendidas por el Tribunal de Estrasburgo" $"$.

\section{LAS SOMBRAS: EL RIESGO DE QUE LA DIGNIDAD HUMANA PIERDA SU CARÁCTER NÚCLEAR}

\section{La difícil, pero esencialísima, relación entre dignidad y libertad}

\footnotetext{
${ }^{13}$ Primeramente, se incorporó al CEDH el protocolo no 6, el 28 de abril de 1983, por el que se prohíbe la pena de muerte excepto en caso de guerra. Posteriormente, en el año 2002 se aprobó el protocolo $\mathrm{n}^{\circ} 13$, que extiende la abolición de la pena de muerte también para el caso de guerra.

${ }^{14}$ Importantes en este punto, entre otras, son las sentencias Soering c. Reino Unido, de 7 de julio de 1989; u Öcalan c. Turquía, de 12 de mayo de 2005.

15 MARGUÉNAUD, J.-P., "Liberté sexuelle et droit de disponer de son corps", Droits. Revuefrançaise de théorie, de philosophie et de culture juridique, nº 49, 2009, p. 21.
} 
La jurisprudencia del TEDH ha dictaminado repetidas veces que la "la dignidad y la libertad del hombre son la esencia misma del Convenio"16. Lo que ocurre es que la relación entre ambos caracteres humanos — relación desde luego compleja ${ }^{17}$ — se ha revelado especialmente problemática en los últimos tiempos, como someramente ilustraremos, y ha sido causa de notables zonas de sombra en la jurisprudencia del Tribunal. Es asunto de la máxima relevancia, pues se ventila el ser del Derecho, su esencia, inextricablemente vinculada al equilibrio cabal entre dignidad humana y autonomía personal, entre libertad y bien social, entre libre albedrío y racionalidad. Pero bien entendido que lo que realmente caracteriza al Derecho es la racionalidad en la determinación de las exigencias derivadas de la dignidad humana. Como ha escrito Martínez López-Muñiz, “el triunfo del Derecho es el triunfo de la razón, del justo discernimiento de las exigencias inherentes a la dignidad de las personas en sus relaciones recíprocas y con las cosas que constituyen su oikos" ${ }^{\prime 18}$.

Los avatares de la historia comportaron que en el siglo $\mathrm{XX}$ - convulso como ningún otro- varias Constituciones y distintos instrumentos internacionales sobre derechos humanos asumieron como basamento de tales derechos, implícita o explícitamente, el concepto de dignidad humana ${ }^{19}$ (se da la circunstancia, no obstante, de que el CEDH no la cita expresamente). Desde ese momento tiene lugar una “juridificación” de una noción de naturaleza filosófica, cuya conceptuación moderna se atribuye de manera especial a Kant: es bien conocido que sentó aquello de que "los seres racionales se denominan personas porque ya su naturaleza los señala como fines en sí mismos, es decir, como algo que no debe ser usado como simple medio"20. Si resulta atinada la vinculación de la excelencia humana con la racionalidad —que

16 Citemos ahora la sentencia S.W. c. Reino Unido, de 22 de noviembre de 1995, ap. 44; y, literalmente lo expresado en el texto, en la sentencia Pretty c. Reino Unido, de 29 de abril de 2002, ap. 65.

${ }^{17}$ El civilista italiano RODOTTA dice de "la relación entre libertad y dignidad" que "a veces aparece como algo inalcanzable". Vid. El derecho a tener derechos, Trotta, Madrid, 2014, p. 150. En Francia, Pierre LE COZ se plantea si esta relación aboca a una "contradicción insoluble": vid. "Dignité et liberté: vers une contradiction insoluble?", Journal International de Bioétique, 2010, vol. 21, n 3, p. 17.

${ }^{18}$ MARTÍNEZ LÓPEZ-MUÑIZ, J.L., Derecho público y Derecho privado, disyuntiva determinante praa el Estado de Derecho, Real Academia de Legislación y Jurisprudencia de Valladolid, Valladolid, 2009, p. 13.

19 Vid. el interesante trabajo de quien presidiera la Corte Interamericana de Derechos Humanos, el profesor GROS ESPIELL, "La dignidad humana en los Instrumentos Internacionales sobre Derechos Humanos", Anuario de Derechos Humanos, Nueva Época, vol. 4, 2003, p. 193.

${ }^{20}$ Vid, KANT, I., Cimentación para la metafísica de las costumbres, Aguilar, $5^{\mathrm{a}}$ ed., Buenos Aires, 1978, pp. 110-111 (original Grundlegungzurmetaphysik du sitten, publicado en 1785). Me ocupé de esto en La dignidad de la persona. Núcleo de la moralidad y el orden público, límite al ejercicio de las libertades públicas, Civitas, Madrid, 2005, pp. 168 y ss. 
determina la capacidad para entender y querer-, así como derivar de esto que la persona no puede ser empleada como medio - solo puede ser sujeto de Derecho, nunca objeto, diríamos en términos jurídicos-, otra cosa es que el filósofo alemán acertara al identificar el fundamento de esta naturaleza racional y de esa dignidad: para él, el fundamento está en la autonomía, de modo que la dignidad humana se reduce al carácter autonormativo y libre del hombre. Esto comporta que "desde los presupuestos kantianos se identifica dignidad y autonomía o libertad" ${ }^{21}$. Incorporo este apunte filosófico porque esta idea late en las propuestas actuales de relación entre ambos conceptos, que luego glosaré.

En mi entendimiento del concepto de dignidad humana, se trata de una dignidad "ontológicamente inherenteo intrínseca a la persona humana"22, poseída sea cual fuera su acogimiento legal efectivo, el comportamiento de esa concreta persona o el trato dispensado por lo demás: se posee dignidad porque se es hombre ${ }^{23}$. Y de tal rango ontológico se deriva el haz de derechos y libertades que enriquecen al hombre, concebidos todos ellos, pues, como manifestaciones o concreciones de aquella dignidad.

Puede fácilmente convenirse que en el núcleo de esa dignidad del hombre se sitúa su libertad, en virtud de la cual toda persona debe poder actuar "de acuerdo con una elección consciente y libre, es decir, personalmente movido e inducido desde dentro"24; esto hasta el punto de que —nos dice un filósofo_- "el hombre es terminantemente hombre por su libertad" 25 .

En este sentido, podríamos decir que el hombre, por tener dignidad, es un ser libre; de modo que goza de una cabal autonomía, de una capacidad de autodeterminación de su vida ${ }^{26}$. De modo que libertad, autonomía y autodeterminación vendrían a ser conceptos ligados, en cierto modo sinónimos. Idea esta que expresa en la

\footnotetext{
${ }^{21}$ Vid. el muy interesante trabajo de CABRERA CARO, L., "Autonomía y dignidad: la titularidad de los derechos", Anuario de Derechos Humanos, no 3, 2002, p. 29.

${ }^{22}$ GROS ESPIELL, H., ibíd., p. 197.

${ }^{23}$ Dice CABRERA CARO al respecto: "la dignidad (...) no se refiere a condiciones concretas de la existencia, sino a un rasgo ontológico que no es adquirido por el hombre ni atribuido por ninguna instancia ajena al mismo: simplemente, se posee por la simple pertenencia a la especie humana". Vid. op. cit., pp. 34-35.

${ }^{24}$ Concilio Vaticano II, Constitución Gaudium et Spes, $\mathrm{n}^{\mathrm{o}} 17$.

${ }^{25}$ CARDONA, C., Metafísica del bien y del mal, Eunsa, Pamplona, 1987, p. 99.

${ }^{26}$ Dice al respecto RODOTTA que "en la antropología moderna de la persona, la dignidad conduce a la autodeterminación”, y de esta segunda recuerda que el Tribunal Constitucional italiana la considera como un derecho fundamental de la persona (op. cit. p. 182).
} 
doctrina francesa la profesora Roman de esta manera: "en una perspectiva tradicional de la filosofía política y moral el concepto de autodeterminación es indisociable del de libertad": esta vendría a ser "un poder de autodeterminación en virtud del cual el hombre elegiría él mismo su comportamiento personal". Y en este sentido, añade, "libertad y autodeterminación serían sinónimas y supondrían el reconocimiento en provecho del individuo de una esfera de acción que escapa a la coacción social"27.

Siendo esto cierto, podemos decir que, hoy más que nunca, la concreción jurídica de la relación entre dignidad y libertad $-\mathrm{y}$ consiguiente autonomía personal o potestad de autodeterminación - se presenta extraordinariamente tormentosa. Bien puede decirse que el entendimiento kantiano de la relación entre dignidad y libertad se ha trasladado con fuerza inusitada al mundo del Derecho: como por influencia del filósofo alemán parece olvidarse que "la libertad — la independencia o la autonomíaes una secuela de la dignidad y no al contrario" ${ }^{28}$. Así, el giro copernicano que en estos momentos toma cuerpo con fuerza y que afecta sobremanera a la recta comprensión del Derecho - está en juego una alteración radical del sistema jurídico-, podría resumirse como sigue. Cabalmente, se partía del axioma de que la dignidad de la persona comportaba - entre otros derechos - que esta era libre para autodeterminarse, para obrar autónomamente; es decir, de la dignidad se derivaba la autonomía personal, tal como la describimos más atrás. Ahora, sin embargo, la base del sistema jurídico amenaza con desplazarse a la autonomía personal, que pasaría a ser la determinante de la dignidad personal: será entonces "digno" no lo que resulte acorde a racionales exigencias de la ontología humana, sino aquello que sea producto de la autodeterminación de la persona. Como expresión de esta inversión Rodotta asume que "la vida digna de ser vivida, entonces, es aquella que la persona autónomamente construye como tal". De aceptarse lo cual la asunción por el hombre de la mayor de las depravaciones morales dará lugar a una "vida digna" siempre que sea producto de una opción personal y libre... ${ }^{29}$. En definitiva, la libertad y la dignidad ven alterada los términos de su relación: la autonomía de la persona deja de ser una manifestación de la

${ }^{27}$ ROMAN, D., “Autodéterminationpersonnelle et choix de vie et choix de mortdans la jurisprudence de la CourEuropéenne", en LEVINET, M. (dir.) Le droitaurespectde la vieausens de la Conventioneuropéenne des droits de l'homme, Nemesis-Bruylant, Bruselas, 2010, p. 253.

${ }^{28}$ CABRERA CARO, L, op. cit., p. 33.

${ }^{29}$ Lo que el autor italiano completa afirmando que "no hay vidas 'indignas' salvo aquellas que otros pretenden construir en nuestro lugar violando así el derecho de auto-representación y de competencia para orientarse en el mundo" (op. cit., p. 196). 
dignidad humana para pasar a ser su configuradora; con lo que tal dignidad pierde su sentido objetivo; ahora será determinada subjetivamente por cada cual. Se produce, pues, lo que Dorn llama "la inversión del orden de los conceptos"30, de enorme relevancia práctica. En definitiva, como dice Serna, el principio de dignidad queda“absorbido por el principio de autodeterminación personal”, con lo que pierde "toda eficacia práctica independiente" 31.

Pienso que se entenderá esta problemática, y sus consecuencias, con los ejemplos que serán analizados más adelante. El caso es que en esta alteración en el sentido de la dignidad humana $-\mathrm{y}$ de la autonomía personal — tiene una enorme responsabilidad la jurisprudencia reciente del TEDH.

\section{El principio de autonomía personal en la jurisprudencia del TEDH: la sentencia Pretty c. Reino Unido}

La jurisprudencia del TEDH parece asumir últimamente un sentido renovado de la autonomía de las personas, seguramente "sin tomar conciencia de que la noción permite un verdadero vuelco en la protección asegurada para los derechos del hombre", en la medida en que es invocada "para justificar violaciones a los derechos del hombre" 32 . Y es que el que el TEDH parece orientado a hacer prevaler el que ha llamado principio de autonomía personal sobre el de dignidad humana ${ }^{33}$.

Y es que en su labor constructiva — de construcción pretoriana, se suele decirde un orden jurídico común a Europa en materia de derechos y libertades, no hace mucho, en 2002, el TEDH consagró explícitamente la "noción”, “derecho" o "principio", que denominó “de autonomía personal”, ausente —al menos

30 DORN GARRIDO, C., "La dignidad de la persona: límite a la autonomía personal”, Revista de Derecho, no 26, 2011, p. 75.

${ }^{31}$ SERNA, P., "La dignidad humana en la constitución europea", en Persona y Derecho, Revista de fundamentación de las Instituciones y de Derechos Humanos, no 52, 2005, p. 57.

${ }^{32}$ FABRE-MAGNAN, M., "Le sadismen'estpas un droit de l'homme”, RecueilDalloz, 2005, n 43, p. 2975.

${ }^{33}$ Vid. LEVINET, M., “La Conventioneuropéenne...”, cit., p. 243. 
explícitamente - del texto del $\mathrm{CEDH}^{34}$. Puede afirmarse que tal principio permanecía inédito en el Derecho europeo, aunque también se ha dicho que los jueces de Estrasburgo no lo "crearon" entonces, sino que sencillamente "afirmaron" algo implícito en el Convenio ${ }^{35}$. El caso es que en su famosa sentencia Pretty c. Reino Unido, de 29 de abril de 2002, en la que se ventilaba la existencia de un supuesto "derecho a la muerte asistida", el TEDH procedió a la consagración explícita del concepto, al que ha otorgado tal relevancia que Edelman dice que "resume toda la doctrina del Tribunal" de los años siguientes ${ }^{36}$. Señaló el Tribunal entonces que "aunque en ningún asunto anterior haya sido establecido que el artículo 8 [derecho al respeto a la vida privada y familiar] comportara un derecho a la autodeterminación como tal, el Tribunal considera que la noción de autonomía personal refleja un principio que sostiene la interpretación de las garantías del artículo 8": sensu contrario, puede entenderse que el TEDH está identificando la autonomía personal con la autodeterminación de las personas, otorgando a esta carta de naturaleza de auténtico derecho. Más adelante, la Sala conceptúa "el principio de autonomía personal” como "la facultad de cada uno de llevar su vida como le parezca", o "el derecho a efectuar elecciones concernientes al propio cuerpo" ${ }^{37}$. Los propios términos empleados por los jueces europeos justifica que Levinet afirme que la "sentencia fundadora" del principio de autonomía personal es “indiscutiblemente" esta sentencia Pretty c. Reino Unido ${ }^{38}$.

El TEDH aclara la extensión del susodicho derecho en relación con la posibilidad de asumir actividades nocivas para la persona: aquella "facultad" de conducción de la propia vida "puede también incluir la posibilidad de entregarse a actividades consideradas física o moralmente perjudiciales o peligrosas para su persona”. Después de esta declaración, la Sala incorpora una explicación de su tesis, en estos términos:

"La medida por la cual un Estado puede recurrir a la coacción o al derecho penal para prevenir a las personas contra las consecuencias del estilo de vida escogido por ellas, ha sido largamente

\footnotetext{
34 LEVINET, M., "La notiond'autonomiepersonnelledans la jurisprudence de la CourEuropéenne des Droits de l'Homme", Droits. Revuefrançaise de théorie, de philosophie et de culture juridique, $\mathrm{n}^{\circ} 49$, 2009 , p. 3.

35 LAGARDE, E., Le principed'autonomiepersonnelle. Étude sur la dispositioncorporelle en droiteuropéen, Université de Pau (2012), tesis doctoral no publicada, pero disponible en los sitios web www.theses.fry www.sudoc.abes.fr; en concreto, vid. p. 30.

${ }^{36}$ Op. cit., p. 124.

${ }^{37}$ Vid. apartados 61, 62 y 66, respectivamente, de la sentencia.

${ }^{38}$ LEVINET, M., "La notion de autonomie...”, cit. p. 6.
} 
debatida, tanto moralmente como jurisprudencialmente, y el hecho de que la injerencia se perciba a menudo como una intrusión en la esfera privada y personal no hace sino añadir vigor al debate. Sin embargo, incluso cuando el comportamiento en cuestión representa un riesgo para la salud o cuando razonablemente se puede considerar que es potencialmente mortal, la jurisprudencia de los órganos del Convenio estima la imposición por parte del Estado de medidas de coacción o de carácter penal atentatoria contra la vida privada, en el sentido del artículo 8.1, y que requiere una justificación conforme al segundo apartado de dicho artículo" (apartado 62).

De entrada, el núcleo del mensaje puede considerarse correcto: en primer lugar, es cierto que la autonomía personal faculta a las personas a realizar actos que puedan resultar nocivos para ellas, por razón de su libertad; y, en segundo lugar, esto no autoriza a cualesquiera comportamientos, de modo también puede justificarse la injerencia estatal en esa autonomía. Pero también es cierto que, tal como se describe la regla y se prevé la excepción, parece que la dignidad ontológica del ser humano cede a la autonomía personal su posición de honor como legitimadora de conductas. Asimismo, es importante resaltar, a favor de la dicción del Tribunal, que se refiere a "estilos de vida" y a "comportamientos" personales, sin referencia alguna a la participación ajena en actos dañosos.

Puede decirse, y es lo importante en este punto, que con esta consagración expresa y esta interpretación del principio de autonomía personal se inicia una vuelta de tuerca en el proceso de valorización excesiva de la autonomía de las personas, que poco a poco ha ido arrinconando los valores que presiden el CEDH, condensados en la primacía de la dignidad humana. La propia sentencia fundadora reitera una declaración axiomática recogida en fallos anteriores — recuérdese: "la dignidad y la libertad son la esencia misma del Convenio"-; pero lo cierto es que pone la semilla para centrar tal esencia en la segunda parte del binomio, en la forma de autonomía personal.

La trayectoria de la noción de autonomía personal era calificada por el profesor Levinet en el año 2009 — es decir, solo siete años después de su irrupciónde la mano del TEDH - como "fulgurante"; esto hasta el punto de considerar en aquel momento su presencia en el panorama del Derecho europeo como "espectacular"39. La palestra jurídica en este campo está, pues, en ebullición. Lo cierto es que la acogida al principio parece coherente con el hecho de que, en la certera valoración que hace el profesor Levinet, las sociedades occidentales parecen cada vez más unidas entorno a la "nueva religión del hipersubjetivismo, del culto a la autonomía personal"40 (subrayados suyos).

\footnotetext{
${ }^{39}$ LEVINET, M., “La notiond'autonomiepersonnelle...”, cit., pp. 4 y 8.

${ }^{40}$ LEVINET, M., Théoriegénerale des droits..., cit., p. 379.
} 
Es claro que las discrepancias en punto a la interpretación de este principio son proverbiales y enormemente trascendentes.

Se entiende, por tanto, que el entusiasmo suscitado por el concepto salido del TEDH -Pena-Soler habla de él como de la "nueva ninfa del mundo de los derechos fundamentales" $"$ _ haya provocado a la par notables inquietudes: estas, como bien expresa Hélène Hurpy, se concentran especialmente en "la liberación de los límites fijados hasta ahora por el Derecho, para la preservación del bien social”42. Sostengo, en este punto, que la función esencial del Derecho es precisamente la tutela bien común social, cuyo núcleo duro lo constituye la preservación de la dignidad humana: cuando el Estado asume esta tarea no ejerce una función paternalista sobre las personas, sino una responsabilidad de carácter social.

Los riesgos de hipervaloración de esta autonomía personal aconseja examinar la interpretación que ha hecho el TEDH en casos concretos. Lo haremos, someramente, en dos supuestos: la disposición de la vida y las prácticas sadomasoquistas.

\section{Dos supuestos relevantes: disposición de la vida y sadomasoquismo}

\section{A) Protección de la vida y eutanasia}

Qué duda cabe de que el cabal discernimiento de las exigencias y límites de la autonomía personal se revela particularmente importante en materia de la tutela de la vida: no en vano el mismo TEDH, en la sentencia Pretty, afirmó del derecho a la vida que sin su protección “el goce de los demás derechos y libertades garantizados por el Convenio sería ilusorio" (ap. 37). Años más tarde, en la sentencia Zavoloka c. Letonia, de 7 de julio de 2009, el Tribunal califica el artículo 2 del CEDH como "la disposición más fundamental del Convenio" (ap. 35).

Es por todo ello que la sentencia Pretty c. Reino Unido reviste una enorme trascendencia.Es una sentencia que, aunque pueda ser compartible en su gran mayoría,

\footnotetext{
41 PENA-SOLER, A., “À la recherche de la liberté personnelledésespérément...”, en Melanges en l'honner de Louis Favoreu, Dalloz-Sirey, París, 2007, p. 1675.

${ }^{42}$ HURPY, H., Funtion de l'autonomiepersonnelle..cit, 2015, p. 27. 
aparece dotada de ciertas dosis de incertidumbre, o incluso de incoherencias. Repasemos algunos de sus puntos clave:

1) La primera circunstancia que llama la atención en esta sentencia es que al precisar el alcance del derecho a la vida del artículo 2 del CEDH afirma que este precepto "no puede crear un derecho a la autodeterminación en el sentido de que conceda a todo individuo el derecho a escoger la muerte antes que la vida" (ap. 39): realiza una declaración relevante que limita de manera muy importante la autonomía personal.

Algo después, en el apartado 41, el TEDH afirma lo siguiente: "la medida con la que un Estado permite o trata de regular la posibilidad para los individuos en libertad de hacerse daño o de que otro les haga daño, puede dar lugar a consideraciones que pongan en conflicto la libertad individual y el interés público que no pueden ser solucionadas sino al término de un examen de las circunstancias concretas del caso”. Los jueces son conscientes de que la presencia de consideraciones de interés general comporta que las circunstancias del caso determinarán una opción por la libertad (que podrá implicar una permisión o tolerancia por parte del poder estatal) o por la intervención pública (si considera que priman las consideraciones de interés general: la antes referida misión estatal de tutela del bien común social).

2) El TEDH incurre más adelanteen una contradicción criticable, ya no en el marco del artículo 2, acerca el derecho a la vida, sino del artículo 8, sobre el respeto a la vida privada: ¿es coherente que después de proclamar "la obligación del Estado de proteger la vida", y de negar un "derecho a morir" o un "derecho a escoger la muerte antes que la vida" (ap. 39 y 40), afirme, taxativamente, que "una persona puede reivindicar el derecho a ejercer su elección de morir rechazando un tratamiento que pudiera prolongar su vida" (ap. 63)? Baste ahora apuntar que el TEDH, en fallos posteriores, no siempre ha sido coherente en este campo de los tratamientos médicos desde el momento en que, por ejemplo, ha admitido la alimentación forzada destinada a salvar la vida de un detenido que rechaza conscientemente alimentarse.

3) Otro ejemplo de incoherencia interna de la sentencia Pretty se localiza en el ap. 74: se afirma que "el Tribunal considera (...) que los Estados tienen el derecho a controlar, a través de la aplicación del derecho penal general, las actividades 
perjudiciales para la salud y la seguridad de los demás". Levinet aplaude esta afirmación, que considera "la gran lección de la sentencia Pretty" "El TEDH, que bien podría haber calificado esta tarea estatal como un "deber" en lugar de un "derecho", acoge así el alterum non laedere del Derecho romano, que impone a toda persona una obligación de no dañar a los demás. Pero, acto seguido, a la hora de determinar la exigibilidad de tal regla en relación al auxilio al suicidio — razón de ser de la causa—, el Tribunal da un giro y, sin explicación suficiente, desplaza la ratio discendi: prescinde del ejecutor de acción dañosa y la sitúa en la víctima, de modo que posa su atención en la virtualidad del principio de autonomía y en una presumible "vulnerabilidad de la categoría a la que pertenecen" las víctimas. La conclusión se presenta tan diáfana como espantosa: para el TEDH, allá donde supuestamente no exista vulnerabilidad, por tratarse de decisiones adoptadas con pleno conocimiento de causa, la autonomía de la víctima podría legalizar la actuación del ejecutor.

En fin, este germen de valorización reforzada de la autonomía personal se vio potenciado, sustancialmente, en sentencias posteriores, en este campo del derecho a la vida y en otros. Veamos uno muy significado.

\section{B) Sadomasoquismo}

Por escabrosa que es, sin duda, la cuestión que abordaremos -el sadomasoquismo: en realidad, una modalidad de trato inhumano o degradante-, no es un asunto menor: en este género de prácticas se afecta de modo directo la integridad física y moral de la persona, que en los textos sobre derechos fundamentales suele aparecer al alimón del derecho a la vida, o acto seguido de este (así, en el art. 15 de la Constitución española). Pienso que los affaires que se citarán resultan extraordinariamente ilustrativos del viraje asumido por el TEDH sobre el papel de la dignidad humana y la autonomía personal, en el sentido de avalar que la segunda (o el "derecho a efectuar elecciones concernientes al propio cuerpo", en términos de la sentencia Pretty) pueda justificar palmarios atentados a la primera con tal de que fueran consentidos. Parto de que "usar" del otro en el propio beneficio (aun con su consentimiento) constituye una de las mayores indignidades que puede cometer el hombre, llamado a relacionarse con los demás seres humanos como personas y no como

\footnotetext{
${ }^{43}$ LEVINET, M., ibíd., p. 15.
} 
si fueran cosas; el hecho de que, además, medien daños corporales solo agrava la indignidad del comportamiento. Dicho esto, paso a hacer un breve relato de las dos causas sustanciadas ante el TEDH acerca del sadomasoquismo, así como su valoración jurídica.

El TEDH se enfrentó por primera vez al sadomasoquismo en el asunto Laskey, Jaggard y Brown c. Reino Unido, resuelto en sentencia de 19 de febrero de 1997. Se trataba de juzgar la inculpación penal de cuarenta y siete homosexuales, adultos, por los golpes y heridas producidas durante las prácticas sadomasoquistas que venían realizando, con un fin de goce sexual, desde hacía una decena de años. Los recurrentes basaron su defensa, sobre todo, en el consentimiento de las "víctimas" y en el carácter secreto de la organización y de las prácticas; pero el Tribunal juzgó las condenas impuestas como "necesarias en una sociedad democrática" para "la protección de la salud". En este sentido, el Tribunal señaló que "uno de los papeles incontestablemente confiados al Estado es la regulación, por el juego del Derecho penal, de las prácticas que entrañen daños corporales. Que estos actos sean cometidos en un marco sexual o en otrono cambia nada" (ap. 43) $)^{44}$.

Sin embargo, el TEDH, en su Sección primera, llevó a cabo en la sentencia K.A. y A.D. c. Bélgica, de 17 de febrero de 2005, un sustancial viraje en relación con su precedente de 1997, que ha merecido durísimos calificativos por parte de la doctrina en particular, francesa y belga-: Levinet dice de ella que resulta "deplorable", y advierte que el giro que provoca "puede legítimamente inquietar" 45 ; Renchon, que fuera decano en Lovaina, afirma que "es una sentencia que impresiona"46; y, en fin, FabreMagnan considera el fallo "inquietante", en cuanto el TEDH esboza "sin que parezca que tome plena conciencia, un verdadero vuelco de la filosofía de los derechos del hombre" 47 . En realidad, a la vista de la entidad del giro operado y, sobre todo, de la

\footnotetext{
44 Procede un breve apunte sobre el voto particular concordante del juez Pettiti en este asunto: a su juicio, era necesario añadiral párrafo 43 de la sentencia que competía al Estado la sanción de abusos sexuales que "no entrañaran daños corporales sino atentados a la dignidad": parte, pues, de que caben indignidades en la relación personal aunque no se causen daños físicos.

${ }^{45}$ LEVINET, M., "La CourEuropéenne des Droits de l'hommeauxprisesavec la pénaliastion du samomasochisme. Réflexions critiques sur les dérives de la'autonomiepersonnelle”, en VVAA L'identitésexuelle. Contuamce et défautcriminel, Dalloz, París, 2008, pp. 192 y 195.

${ }^{46}$ RENCHON, J.-L., “La liberté sexuellen'a-t-elle plus d'autre limite que la liberté sexuelle? A propos de l'arret K.A. et A.D. c. Belgique du 17 février 2005 de la $\mathrm{CEDH}$, en VVAA En hommage à Francis Delpérée. Itinérairesd'unconstitutionnaliste, Bruylant-LGDJ, Bruselas-París, 2007, p. 1309.

${ }^{47}$ Op. cit., p. 2973.
} 
propia incoherencia interna de la sentencia, y hasta del hecho de que se termine dando por buena la condena que se enjuiciaba, no parece descabellada la esperanza manifestada por Gérard Gonzalez de que se trate de "un deslizamiento fantástico de algunos jueces del Tribunal europeo", que él mismo "conseguirá rechazar"48.

En este caso del año 2005 se enjuiciaba la condena penal por prácticas sadomasoquistas extremas (sometimiento a daños físicos graves, que bien podrían calificarse de auténtica tortura), inicialmente consentidas por la víctima - la mujer-, pero que se prolongaron cuando esta había solicitado su cesación. La calificación jurídica de estas prácticas no es baladí: no puede perderse de vista la tradicional consideración de la prohibición de la tortura como norma de ius cogens, indisponible ${ }^{49}$.

Decía antes que la nueva sentencia, si se interpretada como hace buena parte de la doctrina, mostraría una palmaria contradicción interna. Por una parte, el TEDH fue en este caso más expreso que en la sentencia de 1997 al negar al consentimiento un valor justificante: los demandantes, afirmó, no podían pensar que el consentimiento de la víctima podía constituir una causa de justificación que "neutralizase" el elemento legal de la ley penal, pues“el consentimiento de la víctima del delito no constituye una causa de justificación propiamente dicha" (ap. 56). Dicho lo cual, sin embargo, el Tribunal advirtió que "el derecho penal no puede intervenir, en principio, en el ámbito de las prácticas sexuales consentidas que dependen del libre arbitrio de los individuos. Es necesario, por tanto, que existan unos 'motivos particularmente graves' para que se justifique, a efectos del artículo 8.2 del Convenio, la injerencia de los poderes públicos en el ámbito de la sexualidad". A lo que añadió: "Si bien una persona puede reivindicar el derecho a ejercer unas prácticas sexuales lo más libremente posible, el límite a aplicar es el del respeto a la voluntad de la 'víctima' ${ }^{50}$ de tales prácticas"(ap. 86 y 87). En el remate de esta última frase se sitúa, a mi juicio, la gran duda interpretativa: al referirse

48 GONZALEZ, G., "La liberté sexuellevuepar la Coureuropéenne des droits de l'homme: une conceptionoutracière?LiberAmicorum Françoise Ringel, PUAM, Aix-Marsella, 2007, p. 122.

${ }^{49}$ En este punto la Constitución española es más expresa que otros textos: mientras, por ejemplo, la Declaración Universal de Derechos Humanos dice que "nadie será sometido a torturas ni a penas o tratos crueles, inhumanos o degradantes", el artículo 15 afirma que las personas "en ningún caso" pueden ser sometidas a esos tratos.

50 El propio TEDH entrecomilla la palabra "víctima": da la impresión de que los jueces son conscientes que la mujer efectivamente es una víctima, pero el entrecomillado parece indicar que esa condición cede en el caso de mediar el consentimiento. Con agudeza señala Muriel FABRE-MAGNAN: "Que haya una 'víctima' en el asunto no parece un problema, en cuanto es una víctima que consiente" (op. cit., p. 2976). 
el TEDH a "la voluntad de la víctima" como "el límite a aplicar", ¿está pensando en este concreto caso — en el que tal voluntad es finalmente violentada- o, por el contrario, está afirmando que esta voluntad es, in genere, el único límite a aplicar a la autonomía en materia sexual? Creo que la alusión a que el Derecho penal no puede intervenir "en principio" en las acciones consentidas, así como la referencia a motivos "graves" que justifican la "injerencia de los poderes públicos" y al respeto a la mayor libertad "posible" en esta materia, sirven para dar por buena la interpretación de la sentencia que niega aquel viraje frente a su precedente ${ }^{51}$ : y es que el TEDH en ningún momento dice que estos actos brutales hubieran sido legítimos si el consentimiento de la víctima se hubiera mantenido; lo único que afirma taxativamente es que la negativa de la víctima es suficiente para la censura de la conducta; y bien puede pensarse, por coherencia interna, que se está refiriendo a este caso concreto en que el consentimiento estaba ausente. No obstante, no deja de preocupar la falta de concreción del texto acerca de los límites a las prácticas sexuales consentidas: así, se echa en falta una alusión a la dignidad humana como límite infranqueable, más allá de la ausencia de consentimiento.

Nadie duda de la libertad sexual de las personas, como tampoco de que tal libertad no autoriza a todo: es una libertad que tiene sus límites $-\mathrm{o}$ aparece delimitada en su contenido, si se prefiere-; así parece reconocerlo el Tribunal en los textos citados (por eso he resaltado alguna parte en cursiva). Lo relevante a nuestros efectos es determinar cuál es el límite (o la delimitación) de esa libertad. Pues bien, de lo expresado por la Sección primera del TEDH se deduce que el Derecho ampararía todo aquello que fuera consentido por la víctima ${ }^{52}$.Sencillamente, si esto es así, y se proyecta sobre otros ámbitos, el Derecho aparecería desconectado de la dignidad humana, pasando a ocupar la autonomía personal el núcleo del sistema jurídico.

Y es que no se sabe muy bien dónde se detiene esta valoración amplificada de la autonomía personal frente al resto de valores humanos: admitida una disposición de la

51 En este sentido, Emmanuel DREYER considera que la sentencia no se ha interpretado correctamente, en la línea expresada: no condiciona expresamente la legitimidad de cualquier comportamiento al consentimiento. Vid. "La dignitéopposé à la personne”, RecueilDalloz, 2008, n³9, p. 2736.

52 Tampoco el TEDH es muy taxativo al respecto, seguramente consciente de que no todo puede justificarse: no en vano dice, tal como recogimos antes, que "el derecho penal no puede intervenir, en principio, en el ámbito de las prácticas sexuales consentidas"; el intercalar "en principio" revela que el Tribunal parece asumir que el consentimiento no justifica cualquier práctica consentida. Bien es cierto que no especifica qué circunstancias excepcionarían aquella libertad sexual. 
propia persona como la enjuiciada en esta causa no es difícil proyectarla sobre cualesquiera aspectos de la vida de cada cual. No parece lógico que esta omnímoda autonomía se circunscriba al ámbito sexual, como si en esta materia el derecho de autodeterminación gozara de necesariamente márgenes mayores que en otros: parece razonable considerar que la degradación del cuerpo o de la dignidad de los demás debe obtener la misma respuesta del Derecho sea cual sea el móvil del comportamiento, sexual u otro. Como señala la profesora Roman, no es admisible que el consentimiento cree un "halo de inmunidad que proteja a las relaciones sexuales de toda intervención estatal" $" 53$.

\section{CONCLUSIONES}

El problema que nos ha ocupado no está en esta genérica proclama de autonomía de las personas, que parece absolutamente razonable, sin reserva alguna, como manifestación de su dignidad y como expresión de un principio general de libertad individual, sino en su interpretación, en la medida en que tal proclama suponga arrinconar el verdadero núcleo del Derecho de las personas, o del mismo Derecho - la dignidad humana-, para caer en una visión puramente individualista de los derechos personales y de la tarea del Estado en su favor.

La labor del TEDH, interpretativa — y hasta creadora - en materia de derechos, en junto a indudables aciertos, conoce —a mi juicio - zonas de sombra, algunas determinantes. Puede afirmarse que está contribuyendo a extender una visión individualista de los derechos humanos, en la medida que parece ubicar al principio de autonomía personal, o un derecho a la autodeterminación, en el eje del sistema de derechos, en detrimento del de dignidad humana.

El TEDH parece olvidar la cláusula de cierre de la DUDH (su último artículo, el 30): "Nada en la presente Declaración podrá interpretarse en el sentido de que confiera derecho alguno al Estado, a un grupo o a una persona, para emprender y desarrollar actividades o realizar actos tendientes a la supresión de cualquiera de los derechos y

\footnotetext{
${ }^{53}$ ROMAN, D., “Le corps a-t-il des droits que le droitneconnaîtpas?”, RecueilDalloz, 2005, p. 1508.
} 
libertades proclamados en esta Declaración" 54 . Es decir, no puede concebirse derecho alguno - léase un derecho a una libre autodeterminación- que se vuelva contra los derechos humanos: una libertad humana no merecerá el amparo del Derecho — su consideración de derecho- si supone menoscabo de la dignidad y de los derechos en que esta se concreta. Bien comenta esta cláusula el profesor Monereo Pérez cuando afirma que "los derechos se desnaturalizan por su utilización desviada respecto al fin y los principios y valores para los cuales han sido reconocidos dentro del ordenamiento jurídico" $" 55$. La razón de ser de la libertad humana y de cualesquiera de los derechos es servir a la dignidad humana, de la que se derivan; y, por lo tanto, aquellos — libertad, derechos — no pueden, en ningún caso, menoscabar esta — la dignidad-.

Obsérvese que la cláusula interpretativa o de cierre que se acaba de mencionar no especifica a qué acciones se refiere, si estrictamente personales (como el suicidio) o que afecten a otra persona (auxilio al suicidio, sadomasoquismo, prostitución). El Derecho no amparará, por tanto, ninguno de estos comportamientos (que los sancione o no es otra cosa). Merece detenimiento específico el caso de efectiva afectación de la dignidad ajena. Adviértase al respecto que las "Explicaciones sobre la Carta de Derechos Fundamentales" de la Unión Europea ${ }^{56}$ se circunscribe a este supuesto, en su glosa al artículo $1^{\text {o: }}$ además de afirmar que "la dignidad de la persona forma parte de la esencia de los derechos inscritos en la presente Carta" y que "no podrá atentarse contra ella", advierte que "ninguno de los derechos inscritos en la presente Carta podrá utilizarse para atentar contra la dignidad de otras personas". Es decir, ni la propia libertad y la de las víctimas autoriza a participar en acciones que atenten contra la dignidad de otras personas. Que es tanto como decir que no se amparará por el Derecho el quitar la vida a otro (auxiliar al suicidio), dañarlo (perjudicar su integridad física o psíquica), "usar" de él (prostitución)... todo esto, aunque el sujeto pasivo lo consienta. En este punto, por tanto, no puedo sino sumarme al parecer de la profesora FabreMagnan: "el derecho a la libertad individual o a la autonomía personal deducido del

\footnotetext{
${ }^{54}$ Precepto que, con variaciones insignificantes, recogen también los artículos 17 de la CEDH, 5 de los Pactos Internacionales de Derechos Civiles y Políticos y de Derechos Económicos, Sociales y Culturales, y 54 de la Carta de Derechos Fundamentales de la Unión Europea.

${ }^{55}$ Vid. MONEREO PÉREZ, J.L., "Estudio Preliminar. Teoría del abuso del derecho: el abuso de los derechos fundamentales", estudio previo incluido en el libro del autor francés Louis JOSSERAND, $E l$ espíritu de los derechos y su relatividad. Teleología jurídica, Comares, Granada, 2012, p. XV.

${ }^{56}$ Explicaciones redactadas por el Praesidium de la Convención que redactó la Carta. Se publicaron en DOUE C, n 303 , de 14 de diciembre de 2007, p. 17.
} 
artículo 8 del Convenio Europeo no puede en ningún caso ser invocado para validar el consentimiento y la renuncia de una persona a su integridad corporal, en la medida en que esta constituye un derecho del hombre" $" 57$.

Menos podrá el Estado, como regla de principio, anteponer la autodeterminación de las personas a su responsabilidad de tutelante la dignidad de las personas humanas: esta tiene, desde luego, una dimensión ético-pública que la convierte en fundamento del orden político. Además, si uno contempla los ejemplos que se citaron, o tantos otros, fácilmente deducirá quiénes serán los perjudicados habituales de la supervaloración de la autonomía personal y de la postergación de la tutela de la dignidad personal: los más débiles (piénsese en aquellos que desean morir, en las víctimas de los tratos vejatorios o en las prostitutas). No olvidemos que el Derecho debe proteger al débil.

\section{Bibliografia}

ÁLVAREZ, Tomás Prieto. La dignidad de la persona. Núcleo de lamoralidad y elorden público, límite al ejercicio de laslibertades públicas, Civitas, Madrid, 2005.

CABRERA CARO, L., Autonomía y dignidad:latitularidad de losderechos, Anuario de Derechos Humanos, no 3, 2002, p. 29.

CARDONA, C. Metafísica delbien y del mal.Eunsa, Pamplona, 1987, p. 99

Concilio Vaticano II, ConstituciónGaudium et Spes, $\mathrm{n}^{\mathrm{o}} 17$.

COSTA, J.-P., La Coureuropéennedesdroits del'homme: unjugequigouverne?,Mélanges G. Timsit, Bruselas, 2004, p. 67.

DREYER, Emmanuel . La dignitéopposé à la personne. RecueilDalloz, 2008, nº 39, p. 2736.

DORN GARRIDO, C., La dignidad de la persona: límitea laautonomíapersonal, Revista de Derecho, n 26, 2011, p. 75.

EDELMAN, B., Naissance de l'hommesadien, Droits. Revuefrançaise de théorie, de philosophie et de culturejuridique, $\mathrm{n}^{\circ}$ 49, 2009, pp. 124 y 133.

FABRE-MAGNAN, M., Le domaine de l'autonomiepersonnelle. Indisponibilité du corps humain et justicie sociale, RecueilmDalloz, nº 1, 2008, p. 38.

${ }^{57}$ FABRE-MAGNAN, M., “Le domaine de l'autonomiepersonnelle. Indisponibilité du corps humain et justicie sociale", RecueilmDalloz, no 1, 2008, p. 38. 
"Le sadismen'estpas un droit de l'homme", RecueilDalloz, 2005, n 43, p. 2975.

GARCÍA DE ENTERRÍA, E., LINDE PANIAGUA, E., ORTEGA, L. y SÁNCHEZ MORÓN, M.Sistema europeo de protección de losderechos humanos, Civitas ,2a ed. , 1983.

GARCÍA JIMÉNEZ, E., El Convenio Europeo de Derechos Humanos enel umbral delsiglo XXI, Tirantlo Blanc, Valencia, 1998, pp. 33 y ss.

GARCÍA ROCA, J., El Preámbulo, contexto hermenéuticodel Convenio: un instrumento constitucional delorden público europeo, en GARCÍA ROCA, J., y SANTOLAYA, P. (coords.), La Europa de losDerechos. El Convenio Europeo de Derechos Humanos, CEPC, Madrid, 2005, p. 45.

GONZALEZ, G. La libertésexuellevueparlaCoureuropéennedesdroits de l'homme: une conceptionoutracière? LiberAmicorum Françoise Ringel, PUAM, Aix-Marsella, 2007.

GROS ESPIELL, La dignidad humana en los Instrumentos Internacionales sobre Derechos Humanos, Anuario de Derechos Humanos, Nueva Época, vol. 4, 2003.

HURPY, H., Funtion de l'autonomiepersonnelle et protectio des droits de la personnehumaine das les jurisprudencesconstitucionnelles et européenne..Bruylant, Bruselas, 2015.

KANT, I., Cimentación para la metafísica de las costumbres, Aguilar, $5^{\mathrm{a}}$ ed., Buenos Aires, 1978, (original Grundlegungzurmetaphysik du sitten, publicado en 1785).

LAGARDE, E., Le principed'autonomiepersonnelle. Étude sur la dispositioncorporelle en droiteuropéen, Université de Pau (2012), tesis doctoral no publicada, pero disponible en los sitios web $\underline{w w w . t h e s e s . f r y ~ w w w . s u d o c . a b e s . f r ; ~ e n ~ c o n c r e t o, ~ v i d . ~ p . ~} 30$

LE COZ. "Dignité et liberté: vers une contradiction insoluble?.Journal International de Bioétique, 2010, vol. 21, nº 3 .

LEVINET, M., “La CourEuropéenne des Droits de l'hommeauxprisesavec la pénaliastion du samomasochisme. Réflexions critiques sur les dérives de la'autonomiepersonnelle", en VVAA L'identitésexuelle. Contuamce et défautcriminel, Dalloz, París, 2008, pp. 192 y 195.

"La notiond'autonomiepersonnelledans la jurisprudence de la CourEuropéenne des Droits de l'Homme", Droits. Revuefrançaise de théorie, de philosophie et de culture juridique, $\mathrm{n}^{\circ}$ 49, 2009.

. "La Conventioneuropéennedesdroits de l'homme, socle de laprotectiondesdroits de l'hommedansledroitconstitucionneleuropéen", RevueFrançaise de DroitConstitutionnel, $\mathrm{n}^{\circ}$ 86, 2011. 
MARGUÉNAUD, J.-P., "Libertésexuelle et droit de disponer de soncorps", Droits. Revuefrançaise de théorie, de philosophie et de culturejuridique, n 49, 2009.

MARTÍNEZ LÓPEZ-MUÑIZ, J.L., Derecho público y Derecho privado, disyuntiva determinante praa el Estado de Derecho, Real Academia de Legislación y Jurisprudencia de Valladolid, Valladolid, 2009.

MONEREO PÉREZ, J.L., "Estudio Preliminar. Teoría del abuso del derecho: el abuso de los derechos fundamentales", estudio previo incluido en el libro del autor francés Louis JOSSERAND, El espíritu de los derechos y su relatividad. Teleología jurídica, Comares, Granada, 2012.

PENA-SOLER, A., “À la recherche de la liberté personnelledésespérément...”, en Melanges en l'honner de Louis Favoreu, Dalloz-Sirey, París, 2007.

RENCHON, J.-L., “La liberté sexuellen'a-t-elle plus d'autre limite que la liberté sexuelle? A propos de l'arret K.A. et A.D. c. Belgique du 17 février 2005 de la CEDH, en VVAA En hommage à Francis Delpérée. Itinérairesd'unconstitutionnaliste, Bruylant-LGDJ, Bruselas-París, 2007.

RODOTTA.El derecho a tener derechos, Trotta, Madrid, 2014

ROMAN, D., Le corps a-t-il des droits que le droitneconnaîtpas?, RecueilDalloz, 2005.

.Autodéterminationpersonnelle et choix de vie et choix de mortdans la jurisprudence de la CourEuropéenne, en LEVINET, M. (dir.) Le droitaurespectde la vieausens de la Conventioneuropéenne des droits de l'homme, Nemesis-Bruylant, Bruselas, 2010. 